\title{
Civil Participation in Military Innovation: Cooperation between the Defense Industry of Indonesia and Turkey 2010-2018
}

\author{
Partisipasi Sipil dalam Inovasi Militer: Kerjasama \\ Industri Pertahanan Indonesia dan Turki 2010-2018
}

\author{
Luerdi \& Hizra Marisa \\ Universitas Abdurrab
}

\begin{abstract}
ABSTRAK
Studi pertahanan memiliki pemikiran bahwa inovasi militer suatu negara memiliki kaitan dengan politik luar negeri suatu negara; kemudian memberikan motivasi bagi mereka untuk melakukan diplomasi pertahanan. Namun, masih sedikit akademisi yang memberikan perhatiannya dalam hal industri pertahanan, khususnya berkaitan dengan negara middle power dan new emerging power. Penelitian ini bertujuan menjelaskan hubungan antara faktor-faktor pendorong dengan kebijakan Indonesia dalam melakukan kerjasama industri pertahanan dengan Turki. Temuan penelitian ini adalah partisipasi sipil dalam inovasi militer dan kepentingan nasional strategis merupakan faktor penting yang mendorong kerjasama tersebut. Kerjasama Indonesia-Turki meliputi riset dan pengembangan, produksi dan pemasaran bersama beberapa alat peralatan pertahanan dan keamanan. Penelitian ini menggunakan konsep inovasi militer dan diplomasi pertahanan dan melihat bahwa Indonesia mengejar agenda kemandirian teknologi pertahanan. Untuk itu, Indonesia mulai melebarkan relasi pertahanan di luar mitra tradisionalnya.
\end{abstract}

Kata kunci: kerjasama, industri pertahanan, partisipasi sipil, kepentingan nasional strategis, diplomasi pertahanan.

The study of defense sees that military innovationshas a connection to foreign policy; therefore, motivate them to conduct defense diplomacy. However, just few scholars have their concern to defense industry subject, especially amongst middle power and new emerging power. This paper aims to explain the interaction between causal factors and Indonesia's cooperation policy with Turkey in term of defense industry. The research has found that civilian participation within military innovation and strategic national interests were supposed to be significant determinants which encouraged the state to agree on defense industry cooperation with Turkey. The cooperation included joint research and development, production and potential sale of armaments. The research applied the concept of civil-led military innovation as well as defense diplomacy and argues that Indonesia has been pursuing its defense technology independence. Therefore, it diversifies its defense relation beyond its traditional partners.

Keywords: cooperation, defense industry, civilian participation, strategic national interest, defense diplomacy. 
Industri pertahanan merupakan salah satu aspek strategis yang menjadi perhatian bagi negara di dalam konstelasi dunia internasional, termasuk Indonesia. Negara cederung berupaya mengembangkan industri pertahanan untuk memenuhi kemampuan pertahanan dalam menjaga kedaulatannya. Pemerintah Indonesia telah melakukan kerjasama pertahanan melalui diplomasi pertahanan dengan sepuluh negara mitra utama yaitu Amerika Serikat, Australia, Malaysia, Rusia, Tiongkok, Perancis, Singapura, Belanda, India dan Korea Selatan (Syawfi 2009, dalam Laksmana 2012, 263). Secara umum kerjasama tersebut dilakukan untuk meningkatkan kemampuan penangkalan dan mewujudkan stabilitas dan perdamaian di kawasan. Kerjasama pertahanan dalam bentuk latihan militer bersama, pertukaran data intelijen, patroli bersama di sekitar daerah perbatasan dan perdagangan persenjataan telah lazim dilakukan oleh Indonesia.

Penelitian ini akan menjelaskan hubungan faktor-faktor pendorong dengan kebijakan Indonesia melakukan kerjasama industri pertahanan dengan Turki. Kajian dalam penelitian ini termasuk kajian politik luar negeri dan kerjasama pertahanan yang merupakan salah satu isu sentral dalam studi ilmu hubungan internasional. Belum besarnya perhatian para akademisi dan minimnya literatur yang menjelaskan perilaku negara middle power seperti Indonesia dalam mengejar agenda kemandirian industri pertahanan menjadi celah yang ingin diisi oleh penelitian ini.

\section{Kerjasama Pertahanan antara Indonesia dan Turki}

Kerjasama pertahanan dalam bentuk pengembangan industri pertahanan bersama merupakan hal yang relatif baru dan telah mendapatkan perhatian dari pengambil kebijakan strategis di Indonesia. Skema kerjasama yang saling menguntungkan merupakan kriteria pengembangan industri pertahanan Indonesia untuk percepatan peningkatan penguasaan teknologi pertahanan serta menekan biaya pengembangan teknologi dengan memperhatikan kepentingan nasional (Kementerian Pertahanan 2015, 69). Model kerjasama tersebut bertujuan untuk mengurangi ketergantungan pasokan alat peralatan pertahanan dan keamanan (alpalhankam) Indonesia dari negara-negara lain. Hal ini juga sebagai jalan menuju kemandirian sistem pertahanan nasional. Tujuan tersebut pada dasarnya sesuai dengan arah kemandirian industri pertahanan Indonesia dalam rangka mencapai industri pertahanan yang kuat, mandiri dan berdaya saing (Kementerian Pertahanan 2015, 63).

Indonesia dan Turki memiliki kesamaan, yaitu merupakan aktor penting kawasan. Indonesia sering dianggap sebagai salah satu kekuatan middle power di Asia Pasifik yang telah memberikan kontribusi dalam mewujudkan stabilitas dan keamanan kawasan. Kondisi ini didukung oleh kemandirian dan modernisasi pertahanan sebagai strategi Indonesia untuk menjaga peran strategic autonomy dalam mengejar agenda-agenda diplomasi di kawasan (Gindarsah \& Priamarizki 2015, 141). Di sisi lain, selain merupakan anggota North Atlantic Organization Treaty (NATO), Turki saat ini merupakan new emerging power yang memiliki prestasi dalam hal mewujudkan kemampuan self-sufficience atau self-reliance dalam industri pertahanan domestik (MacGillivray 2016, 16-17) dan membangun daya saing industri pertahanannya terhadap negara-negara lainnya (Bilgen 2010, 64), sehingga mampu menghadapi ancaman keamanan domestik dan regional tanpa atau hanya sedikit tergantung pada pasokan persenjataan dari luar (Bağcı \& Kurç 2016, 3). 
Kerjasama industri pertahanan Indonesia dengan Turki dimulai dengan kunjungan Presiden Susilo Bambang Yudhoyono ke negara tersebut dan penandatanganan kesepakatan dalam bentuk memorandum of understanding (MoU) oleh kedua negara pada 29 Juni 2010. Indonesia meratifikasi MoU tersebut empat tahun kemudian dan ratifikasi tersebut dituangkan dalam Undang-Undang Republik Indonesia Nomor 19 Tahun 2014 tentang Pengesahan Persetujuan Kerjasama Industri Pertahanan antara Pemerintah Republik Indonesia dan Pemerintah Republik Turki. Pada kerjasama tersebut, kedua pihak sepakat untuk melakukan pengembangan industri pertahanan secara bersama, meliputi penelitian dan pengembangan, modernisasi, produksi, pemasaran dan lainnya (UU No.19 2014). Selain itu, kedua negara juga berkomitmen untuk mengedepankan kepentingan, keamanan dan integritas masing-masing. Undang-Undang tersebut merupakan payung hukum bagi pemerintah Indonesia untuk memulai kerjasama industri pertahanan yang konkret dengan pemerintah Turki. Selanjutnya mengenai hal-hal teknis dan operasional, berbagai kesepakatan telah dibuat oleh kedua pihak dengan melibatkan Kementerian Pertahanan dan perusahaan-perusahan industri pertahanan domestik yang semakin intens paska kunjungan Presiden Joko Widodo ke Turki pada 2017 yang lalu.

\section{Tinjauan Pustaka}

Ada beberapa literatur yang telah menggambarkan ataupun menjelaskan berbagai fenomena yang relevan dengan kajian penelitian ini. Laksmana (2012) meyakini bahwa diplomasi pertahanan bilateral Indonesia dapat dikategorikan ke dalam tiga fungsi yaitu diplomasi pertahanan bagi confidence building measurements (CBM), diplomasi pertahanan untuk peningkatan kapabilitas pertahanan dan diplomasi pertahanan untuk perkembangan industri pertahanan domestik. Amrullah (2016) menggambarkan diplomasi pertahanan Indonesia terhadap Turki dengan konsep diplomasi pertahanan itu sendiri. Diplomasi pertahanan tersebut bertujuan untuk pengembangan industri pertahanan domestik selain berkontribusi pada peningkatan hubungan kedua negara dan kapabilitas militer Indonesia.

Gindarsah (2015) menguraikan bahwa diplomasi pertahanan Indonesia dengan strategi pembendungan (hedging strategy) merupakan pilihan yang terbaik bagi para pengambil keputusan di Indonesia di tengah-tengah ketidakpastian akibat persaingan great power di kawasan. Diplomasi pertahanan tersebut memiliki dua agenda strategi pembendungan yaitu strategic engagement dan modernisasi militer yang bertujuan untuk mengurangi dampak dari perubahan-perubahan geopolitik, namun tetap menjaga kemampuan bertahan (defensive capability) negara dalam menghadapi ketidakpastian di kawasan.

Sukma (2012) menggambarkan tantangan yang dihadapi oleh lingkungan keamanan dan pertahanan Indonesia di tengah-tengah pengalaman dan kemampuan Indonesia dalam menjaga stabilitas ekonomi dan politik keamanan domestiknya. Walaupun Indonesia menghadapi sejumlah tantangan lingkungan internal dan eksternal, Indonesia percaya diri dengan keberadaan ASEAN sebagai wadah kerjasama multilateral yang mampu memberikan jaminan stabilitas internal dan keamanan eksternal. Hartati, Muhammad, Bayu dan Tasrif (2014) membandingkan berbagai konsep model industri pertahanan beberapa negara dan mencari konsep model ideal bagi pengembangan industri pertahanan Indonesia. Indonesia saat ini sedang menerapkan 
upaya self-sufficient chain dalam memenuhi kebutuhan pertahanan nasional dengan memanfaatkan teknologi produksi sipil domestik. Selain mengandalkan industri pertahanan domestik, kerjasama internasional dalam bentuk kerjasama industri pertahanan juga perlu dilakukan agar dapat berbagi resiko, meningkatkan kapasitas dan memperluas pasar. Kuah dan Loo (2004) mengkaji hubungan antara industri pertahanan dan pertumbuhan ekonomi pada kasus negara Singapura. Perkembangan industri pertahanan Singapura dimulai di saat-saat ekonomi negara tersebut tumbuh dengan baik berkat intervensi pemerintah secara langsung terhadap industri pertahanan dan stabilitas domestik sebagai syarat pertumbuhan ekonomi. Singapura saat ini mulai meninggalkan paradigma merkantilisme dalam pengembangan industri pertahanan dan beralih pada paradigma liberalisme, di mana industri pertahanannya berkontribusi pada pertumbuhan ekonomi, mampu menyerap tenaga kerja dan memperoleh keuntungan melalui ekspor teknologi pertahanan.

Literatur di atas mendukung isu pada penelitian ini di mana pertahanan dan pengembangan industri pertahanan merupakan isu vital dalam pembangunan negaranegara. Namun, literatur di atas masih menyisakan celah (research gap) berupa ketiadaan penjelasan bagaimana kebijakan industri pertahanan dihasilkan khususnya dalam kasus Indonesia dengan Turki. Selain itu, relasi pertahanan Indonesia dengan Turki belum mendapatkan perhatian dari para akademisi dibandingkan relasi pertahanan Indonesia dengan negara-negara di kawasan Asia Timur ataupun Asia Pasifik. Penelitian ini mencoba mengisi celah tersebut dengan memberikan perhatian pada partisipasi sipil dalam inovasi militer yang mendorong praktik diplomasi pertahanan untuk mengejar kepentingan nasional strategis.

\section{Inovasi Militer dan Diplomasi Pertahanan dalam Kerjasama Industri Pertahanan}

Penelitian ini menggunakan konsep inovasi militer dan diplomasi pertahanan untuk menjelaskan kerjasama industri pertahanan Indonesia dengan Turki. Kerangka konseptual tersebut dapat dilihat pada ilustrasi berikut:

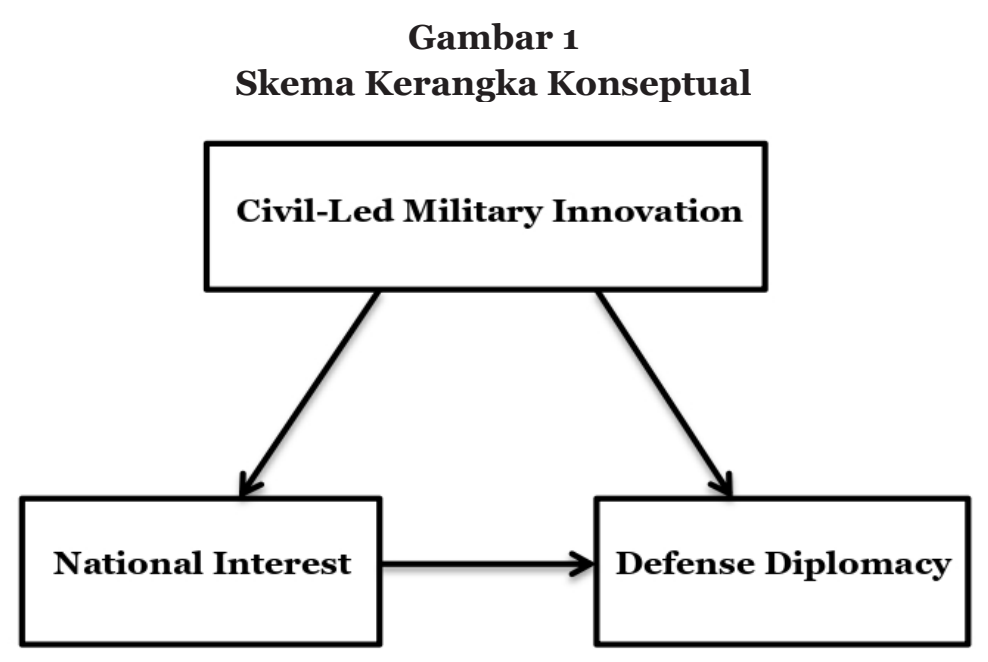




\section{Inovasi Militer}

Inovasi militer merupakan konsep yang masih diperdebatkan. Hal ini disebabkan karena beberapa ahli melihat konsep tersebut dengan sudut pandang atau titik tekan yang berbeda-beda. Konsep inovasi militer senantiasa berada dalam kerangka Revolution in Military Affairs (RMA). Jablonsky (1994 dalam Gleeson 1998) mendeskripsikan RMA sebagai efek holistik dari kerangka integrasi doktrin dan organisasi yang dilengkapi oleh kapabilitas, seperti informasi, dan kemampuan untuk mengeksekusi kapabilitas tersebut, (seperti persenjataan dan lainnya) yang disediakan oleh teknologi. Sedangkan Cooper $(1994,1)$ berpandangan bahwa RMA tidak sekedar teknologi militer atau sistem yang baru, tapi ia juga melibatkan isu-isu operasional dan organisasional yang kompleks. Walaupun demikian, inovasi militer merupakan bagian penting dari kerangka RMA, baik itu bersifat doktrinal ataupun teknis, yang bertujuan mengejar efektifitas kapabilitas militer (Gleeson 1998, 6). Dengan kata lain, inovasi militer dapat terjadi pada aspek hardware (teknologi alpalhankam) dan software (budaya dan organisasi) militer.

Inovasi militer merupakan proses dan juga hasil, tidak terjadi dengan sendirinya, dan membutuhkan faktor stimuli yang datang dari luar. Dalam kerangka analisis hubungan sipil-militer Barry R. Posen, partisipasi atau intervensi sipil dan ancaman merupakan determinan utama yang mendorong inovasi militer (Raska 2016, 3). Partisipasi sipil muncul sebagai akibat adanya persepsi ancaman yang berasal dari struktur sistem internasional yang anarki dan mempengaruhi pengambilan kebijakan militer melalui mekanisme organisasional.

Dengan keberadaan kepemimpinan sipil di posisi strategis, sipil dapat berperan dalam melakukan audit terhadap organisasi militer untuk memastikan bahwa mereka melaksanakan jenis operasi militer yang sesuai, mengupayakan tujuan politik sesuai dengan sarana militer serta memastikan perubahan gejala-gejala politik dan perkembangan teknologi (Posen 1984, 241). Selain itu sipil juga bisa berperan sebagai pelindung bagi para reformis militer dan penentu berbagai konsep yang saling bersaing (Millet 1996, 361). Selain dari aspek peran, partisipasi sipil juga dapat terjadi dalam kerangka legal pembuatan kebijakan negara (Gleeson 1998, 18). Contoh umum yang sering terjadi adalah pembuatan Undang-Undang berkaitan dengan urusan militer oleh badan legislatif atau aturan lain melalui mekanisme legal lainnya.

Ada beberapa syarat terjadinya partisipasi sipil diantaranya kekalahan dalam perang yang dialami negara, ketidakpuasan sipil terhadap aspek militer atau pelayanan tertentu dan pertimbangan lingkungan strategis (Posen 1984, 57). Walaupun pemicu partisipasi sipil beragam, kepentingan nasional tetap menjadi prioritas dalam inovasi militer. Berdasarkan tingkat pencapaiannya, Murray (1996, 306-309) membedakan inovasi militer ke dalam dua bentuk; evolusioner dan revolusioner. Inovasi militer yang evolusioner merupakan akumulasi serangkaian inovasi kecil yang menghasilkan perubahan signifikan dalam operasi dan kapabilitas militer, sedangkan inovasi militer revolusioner merupakan gejala kepemimpinan yang bersifat top-down yang memiliki kapasitas pengetahuan tentang aspek-aspek teknis dan konseptual dari inovasi. Aspek revolusioner juga dilihat dari lompatan signifikan dari kemampuan yang ada saat ini (Gleeson 1998, 27).

Pada kasus ini, partisipasi sipil dalam kerjasama Indonesia dan Turki dapat dilihat dari serangkaian diplomasi yang dilakukan oleh pemerintah Indonesia terhadap Turki, 
yang tidak hanya melibatkan organisasi militer (Kementerian Pertahanan) tapi juga non-militer (berbagai kementerian lainnya, termasuk perusahaan industri pertahanan domestik) yang berada di bawah koordinasi Komite Kebijakan Industri Pertahanan (KKIP). Selain itu, penilaian oleh Komisi I serta ratifikasi MOU kerjasama oleh DPR merupakan bentuk partisipasi sipil yang memberikan andil terwujudnya kerjasama tersebut. Sedangkan model dan tujuan yang ingin dicapai dari kerjasama industri pertahanan kedua negara melalui diplomasi pertahanan merupakan inovasi militer dilihat dari aspek hardware.

\section{Diplomasi Pertahanan}

Istilah diplomasi pertahanan pertama kali digunakan oleh Kementerian Pertahanan Kerajaan Inggris pada 1990-an untuk mengkonsolidasikan serangkaian aktivitas militer kooperatif (Winger 2014, 2). Winger (2014, 11), dengan pendekatan statecraft (power), mendefinisikan diplomasi pertahanan sebagai penggunaan institusi-institusi pertahanan negara secara damai untuk mengkooptasi institusi-institusi pemerintahan negara lain demi mendapatkan hasil yang diinginkan. Sedangkan dari pendekatan jenis aktivitasnya, Cottey dan Forster $(2016,5)$ mendefinisikan diplomasi pertahanan sebagai penggunaan sumber daya pertahanan untuk tujuan-tujuan kerjasama di masamasa damai dan infrastruktur terkait khususnya Kementerian Pertahanan sebagai alat politik luar negeri dan kebijakan keamanan.

Mengacu pendapat Cottey dan Forster tersebut, konsep diplomasi pertahanan telah mengubah paradigma terhadap angkatan bersenjata yang secara tradisional dianggap sebagai sarana efektif dalam penggunaan ancaman atau kekerasan. Aktivitas dalam diplomasi pertahanan juga telah melebar dari awalnya sebagai upaya melakukan balance of power atau membentuk aliansi sampai pada kerjasama pertahanan dan misi-misi kemanusian. Begitu juga dengan aktor yang terlibat, institusi militer bukan satu-satunya dalam aktivitas diplomasi pertahanan.

Hills $(2000,47)$ berpendapat reformasi sektor keamanan juga menjadi penting dalam aktivitas diplomasi pertahanan yang dapat dilakukan melalui berbabagi kegiatan bantuan militer seperti pelatihan dan inisiatif lainnya. Dalam hal ini, Kementerian Pertahanan perlu berkoordinasi dengan baik dengan berbagai kementerian lainnya yang memiliki fungsi melengkapi agar reformasi sektor keamanan dapat berlangsung. Diplomasi pertahanan memiliki lima fungsi dasar, (1) mengumpulkan dan menganalisis informasi berkaitan dengan angkatan bersenjata dan situasi keamanan, (2) mempromosikan kerjasama, komunikasi dan hubungan timbal balik diantara angkatan bersenjata, (3) mengorganisasikan dan memelihara hubungan pertahanan resmi negara, (4) mendukung ekspor alpalhankam, dan (5) mewakili bangsa dan angkatan bersenjata pada agenda-agenda resmi dan kegiatan-kegiatan yang serupa (Sanyal, 2018).

Diplomasi pertahanan memiliki tiga karakteristik, yaitu: (1) diplomasi pertahanan untuk confidence building measures, yang dilakukan untuk meningkatkan hubungan baik antar bangsa, mengurangi tensi dan mispersepsi, mempromosikan keterbukaan dan transparansi dalam peningkatan kapabilitas militer; (2) diplomasi pertahanan untuk kapabilitas pertahanan, yang bertujuan untuk meningkatkan kemampuan pertahanan bangsa dalam menghadapi ancaman, dan (3) diplomasi pertahanan untuk industri pertahanan, yang bertujuan untuk mengembangkan industri pertahanan negara (Multazam 2010, dalam Sari at al. 2018, 79) 
Namun, diplomasi pertahanan untuk tujuan pengembangan industri pertahanan belum banyak mendapat perhatian. Relasi diplomasi pertahanan dengan industri pertahanan seringkali hanya dikaitkan dengan hubungan perdagangan persenjataan dua negara atau lebih yang kemudian berdampak pada menguatnya hubungan diplomatik di antara negara-negara tersebut. Sedangkan, perkembangan teknologi militer dan kemampuan menginvestasikannya menjadi industri akan menjadi sumber material yang cukup untuk merespon ancaman dan dalam jangka panjang menjadi pemain global. Selain itu, industri pertahanan juga dapat dilihat dari perspektif ekonomi politik di mana negara dapat memperluas pasar bagi inndustri pertahanannya. Politik luar negeri yang independen dan universal seharusnya selalu dilaksanakan untuk melengkapi penguatan kebijakan pertahanan yang hanya dapat dicapai dengan elemen Industrial Defense Base (IDB) (Mello, dalam Ambros 2017). IDB secara instrinsik berkaitan dengan kapabilitas pertahanan mandiri negara yang menjadi penjamin diplomasi yang aktif dan berdaulat (Ambros 2017, 146).

Dalam pelaksanaan diplomasi pertahanan sebagai instrumen politik luar negeri, kepentingan nasional tetap menjadi tujuan utama. Dalam penelitian ini, Indonesia mengejar kepentingan nasional strategis berupa pengembangan atau pemberdayaan industri pertahanan domestik yang meliputi alih teknologi, peningkatan kapasitas pertahanan (deterrence) dan perluasan pasar bagi industri pertahanan. Untuk jangka panjang, kerjasama industri pertahanan dengan Turki diharapkan mampu berkontribusi dalam mewujudkan kemandirin industri pertahanan Indonesia.

\section{Metode Penelitian}

Penelitian ini menggunakan pendekatan kualitatif dengan analisis eksplanasi yang mencoba mencari hubungan kausal antara variabel independen dengan variabel dependen. Variabel independen merujuk pada faktor-faktor (determinan) yang mendorong kebijakan Indonesia melakukan kerjasama Industri pertahanan dengan Turki. Sedangkan variabel dependen merujuk pada kebijakan kerjasama tersebut. Penelitian ini merupakan penelitian kepustakaan di mana buku, penelitian jurnal, laporan penelitian, makalah penelitian, kertas kerja dan dokumen-dokumen lainnya baik cetak maupun daring menjadi sumber data.

Dalam analisis data, penelitian ini menggunakan teknik induksi analitis yang dalam prosesnya seorang peneliti mencari penjelasan universal pada fenomena yang dikaji mulai dari pengumpulan data sampai pada penemuan kasus yang menyimpang dari hipotesis (Bakry 2017, 192). Model analisis data ini terdiri dari: (1) menentukan definisi kasar pertanyaan penelitian; (2) menentukan penjelasan hipotetik dari pertanyaan penelitian tersebut; (3) mengumpulkan data dan memeriksa kasuskasus; (4) mengonfirmasi hipotesis bila kasus menyimpang tidak ditemukan; dan (5) namun, bila kasus menyimpang ditemukan, maka peneliti harus membentuk kembali hipotesis dan mengumpulkan data lebih untuk memeriksa kasus, atau mendefinisikan kembali penjelasan hipotetik untuk menyingkirkan kasus yang menyimpang tersebut (Bryman, dalam Bakry 2017, 193).

Teknik induksi analitis ini menekankan pada pentingnya mengonfirmasi, membentuk kembali hipotesis dan mendefinisikan kembali penjelasan hipotetik selama proses pengumpulan data dan pemeriksaan kasus-kasus. Walaupun kasus yang diperiksa 
terkonfirmasi, seorang peneliti harus tetap mengumpulkan data untuk menghasilkan penjelasan hipotetik yang kuat dalam penelitiannya. Adapun penjelasan hipotetik yang dihasilkan dalam proses teknik analisis ini adalah bahwa Indonesia melakukan kerjasama Industri pertahanan dengan Turki dipengaruhi oleh berbagai faktor seperti partisipasi sipil dalam inovasi militer dan kepentingan nasional strategis.

\section{Faktor Pendorong Kerjasama Industri Pertahanan Indonesia dengan Turki}

Berdasarkan penjelasan konseptual yang telah diuraikan, kerjasama industri pertahanan Indonesia dengan Turki didorong oleh berbagai faktor seperti partisipasi sipil dalam inovasi militer dan kepentingan nasional strategis.

\section{Partisipasi Sipil}

Partispasi sipil dalam pengembangan industri pertahanan Indonesia semakin kuat sejak penerapan paradigma baru pengelolaan industri pertahanan secara resmi setelah Undang-Undang Nomor 16 tahun 2012 tentang Industri Pertahanan disahkan. Untuk memastikan pelaksanaan pengembangan industri pertahanan domestik dan harmonisasi antar organisasi, maka KKIP dibentuk dan strukturnya didominasi oleh sipil. KKIP diketuai oleh Presiden dan beranggotakan sebelas menteri dan kepala lembaga dari berbagai kementerian dan lembaga yaitu Kementerian Pertahanan, Kemen-BUMN, Kemenperin, Kemenristekdikti, Kemendikbud, Kemenkominfo, Kemenkeu, Kemenlu, Bapenas, TNI dan Polri (KKIP 2018). Dengan demikian, sipil dapat berperan lebih leluasa dalam proses pengambilan keputusan berkaitan dengan industri pertahanan. Ini sesuai kerangka hubungan sipil-militer di mana partisipasi sipil dapat terjadi bila sipil menduduki pos-pos strategis dalam urusan militer.

KKIP merupakan komite yang mewakili pemerintah Indonesia dalam mengkoordinasikan kebijakan nasional dalam perencanaan, perumusan, pelaksanaan, pengendalian, sinkronisasi, dan evaluasi industri pertahanan demi mewujudkan kemandirian pemenuhan alpalhankam (KKIP 2018). Dalam hal sebagai koordinator, KKIP berperan dalam mengkoordinasikan pelaksanaan dan pengendalian kebijakan nasional industri pertahanan termasuk mengkoordinasikan kerjasama luar negeri dalam rangka memajukan dan mengembangkan industri pertahanan (KKIP 2018).

Diplomasi yang dilakukan oleh Indonesia terhadap Turki meliputi diplomasi G to $\mathrm{G}$ (antar pemerintah kedua negara, khususnya Presiden dan Kemenlu), $\mathrm{M}$ to M (antar Kementerian Pertahanan kedua negara) dan B to B (antar perusahaan industri pertahanan dan kementerian terkait kedua negara). Artinya, diplomasi yang dilaksanakan oleh Indonesia tidak hanya menitikberatkan pada peran organisasi militer semata. Dalam hal ini, sipil dalam mekanisme KKIP memastikan bahwa arah kerjasama industri pertahanan sesuai dengan kepentingan mencapai kemandirian industri pertahanan.

Partisipasi sipil juga dapat dilihat dari kerangka legal pembuatan keputusan mulai dari pemeriksaan sampai pada pembuatan Undang-Undang. Komisi I dan DPR tidak dapat dipisahkan dalam kerjasama industri pertahanan Indonesia dengan Turki. Persetujuan harus diberikan oleh komisi I sebagai mitra pemerintah dalam urusan kerjasama luar negeri. Paska penandatangan MOU kerjasama, delegasi Komisi I 
melakukan kunjungan ke Turki serta mengadakan pertemuan dengan berbagai pemangku kepentingan untuk mengumpulkan informasi serta melihat perkembangan industri pertahanan negara tersebut agar memudahkan penyusunan Rancangan Undang-Undang (RUU) berkaitan dengan kerjasama industri pertahanan kedua negara (Komisi I DPR RI 2011).

Komisi I juga bertindak melakukan penilaian terhadap rencana kerjasama pemerintah dengan melihat kepentingan nasional berupa peningkatkan kapasistas industri pertahanan. Dengan mengacu pada Undang-Undang Republik Indonesia Nomor 16 Tahun 2012 tentang Industri Pertahanan yang menekankan pada pemenuhan kebutuhan alpalhankam domestik dan kemandirian industri pertahanan nasional, RUU kerjasama industri pertahanan Indonesia dengan Turki disahkan menjadi Undang-Undang Republik Indonesia Nomor 19 Tahun 2014. Ratifikasi yang dilakukan oleh DPR merupakan bentuk partisipasi sipil. Dengan ratifikasi tersebut, pemerintah Indonesia memiliki payung hukum melaksanakan program-program nasional strategis yang bekerjasama dengan Turki.

Sebagai negara demokrasi dengan prinsip pluralisme dalam pengambilan keputusan, partisipasi sipil memiliki pengaruh signifikan termasuk dalam urusan militer atau pertahanan di Indonesia. Kuatnya partisipasi sipil dalam kerjasama Indonesia dengan Turki lebih banyak disebabkan oleh kerangka legal yang berlaku. Berdasarkan kerangka konseptual yang digunakan, inovasi militer yang didorong oleh sipil ini tetap bertujuan mengejar kepentingan nasional.

\section{Kepentingan Nasional Indonesia terhadap Turki}

Politik luar negeri dan diplomasi pertahanan Indonesia dalam kerjasama industri pertahanan didorong oleh analisis lingkungan strategis domestik dan internasional. Indonesia merupakan negara kepulauan yang sangat luas sehingga memerlukan kemampuan ekonomi dan militer yang kuat untuk menjaga kedaulatan tersebut. Namun, relasi kemampuan ekonomi dan militer yang dimiliki menjadi kelemahan dalam menjalankan fungsi pertahanan maksimal negara. Rasio anggaran pertahanan (militer) terhadap PDB setiap tahunnya hanya berkisar di bawah satu persen dan akumulasi belanja pegawai dan barang masih mendominasi peruntukan anggaran dibandingkan belanja modal (alpalhankam) (Panjaitan 2016, 3-4). Situasi tersebut dapat menjadi penghambat pemenuhan minimum essensial forces (MEF) Indonesia.

Ketergantungan terhadap pasokan alpalhankam dari mitra utama juga memiliki risiko bagi politik luar negeri dan intervensi asing dalam masalah domestik. Embargo persenjataan yang pernah dilakukan oleh Amerika Serikat dan intervensi Australia dalam separatisme Timor Timur menjadi pengalaman bagi Indonesia (Laksmana 2012, 263). Sebagai konsekuensi ketergantungan pasokan alpalhankam dari luar, Indonesia saat ini memiliki 173 varian sistem persenjataan yang berasal oleh 17 negara pemasok sehingga mempersulit kesiapan lintas pengoperasian dan menyebabkan peningkatan beban pemeliharaan (Sebastian \& Gindarsah 2013, 300-301). Situasi ini dipersulit dengan industri pertahanan domestik yang belum kompetitif karena masih rendahnya sumber daya manusia, kurangnya riset dan program pengembangan di bidang pertahanan (Tippe 2013, 88).

Indonesia menyadari kecenderungan bahwa negara-negara sedang berupaya mewujudkan kemandirian teknologi pertahanan melalui pemberdayaan industri 
pertahanan domestik. Adanya globalisasi produksi persenjataan paska Perang Dingin memungkinkan negara-negara tersebut untuk memenuhi kebutuhan alpalhankam domestik baik secara mandiri ataupun bekerjasama dengan negara lain yang dianggap memiliki penguasaan teknologi yang lebih maju dalam bentuk pengembangan dan produksi bersama, kemitraan, mergers dan akuisisi, maupun joint ventures (Kurc \& Bitzinger 2019, 1). Selain dapat menekan biaya, interaksi kerjasama juga menciptakan peningkatan perdagangan persenjataan bersamaan dengan kebijakan industri pertahanan negara-negara yang berorientasi ekspor. SIPRI $(2018,1)$ mencatat telah terjadi peningkatan transfer persenjataan global yang tidak hanya melibatkan major powers tapi juga negara-negara kecil. Indonesia melihat adanya peluang untuk menutupi kelemahan pertahanan domestik berupa ketertinggalan dalam penguasaan teknologi pertahanan, keterbatasan alpalhankam strategis dan ketergantungan pada negara-negara besar, dengan cara melakukan kerjasama industri pertahanan. Turki merupakan salah satu negara yang menjadi sasaran diplomasi pertahanan Indonesia karena memiliki reputasi yang baik dalam membangun IDB dan kemandirian industri pertahanan domestiknya. Selain itu, sebagai anggota NATO, alpalhankam yang diproduksi Turki memiliki kualifikasi organisasi pertahanan tersebut.

Kepentingan yang dikejar oleh Indonesia terhadap Turki adalah alih teknologi dan pemenuhan alpalhankam domestik untuk fungsi deterrence. Kepentingan ini dapat dicapai karena model kerjasama yang dilakukan dalam bentuk pengembangan dan produksi bersama. Dalam hal ini, Indonesia terlibat dalam proses prencanaan, penelitian, pengembangan hingga produksi. Jaminan alih terknologi sama pentingnya dengan pemenuhan alpalhankam karena Indonesia akan mampu memproduksi sendiri di masa akan datang sehingga memungkinkan untuk mengurangi ketergantuangan pasokan alpalhankam dari negara lain secara bertahap.

Selain itu, Indonesia juga melihat kemungkinan ekspor persenjataan sebagai konsekuensi peningkatan kapasitas industri pertahanan domestik yang diperoleh melalui kerjasama. Turki memiliki reputasi sebagai negara yang memiliki pasar yang cukup luas bagi industri pertahanannya. Dalam rentang 2013-2017, Turki menduduki posisi ke-15 dari 25 negara top exporters dunia (SIPRI, 2). Kerjasama yang dilakukan oleh Indonesia dengan Turki juga memuat kesepakatan pemasaran bersama dan dengan cara tersebut, Indonesia akan mampu memperluas pasar bagi industri pertahanannya.

Kerjasama yang dilakukan oleh Indononesia dengan Turki merupakan inovasi militer untuk mengembangkan teknologi pertahanan domestik. Kerjasama kedua negara tersebut menjadi contoh bahwa Indonesia mulai meninggalkan skema kerjasama lama yang hanya mengandalkan pasokan alpalhankam dari luar (sebagai pembeli). Kerjasama tersebut sesuai dengan strategi nasional untuk kemandirian pertahanan yang bersandar pada pengembangan industri pertahanan domestik.

\section{Macam - Macam Kerjasama Industri Pertahanan Indonesia dengan Turki}

Paska ratifikasi, pemerintah Indonesia segera menindaklanjuti rencana kerjasama industri pertahanan dengan pemerintah Turki yang didorong oleh faktor-faktor di atas. Dalam implementasi kerjasama tersebut, kedua pihak melibatkan perusahaanperusahaan industri pertahanan domestik yang akan bertanggungjawab dalam tataran teknis dan operasional. Adapun berbagai bentuk kerjasama industri peratahanan yang telah disepakati adalah sebagai berikut: 


\begin{tabular}{|c|c|c|}
\hline Indonesia & Turki & Bentuk Kerjasama \\
\hline PT. Pindad & FNSS & $\begin{array}{l}\text { Transfer teknologi, produksi lokal dan } \\
\text { produksi bersama Modern Medium-Weight } \\
\text { Tank (MMWT) atau Kaplan MT. }\end{array}$ \\
\hline PT. Len & Aselsan & $\begin{array}{l}\text { Produksi bersama peralatan komunikasi } \\
\text { militer untuk HF dan V/UHF teknologi } \\
\text { software defined radio (SDR). }\end{array}$ \\
\hline $\begin{array}{c}\text { PT. } \\
\text { Dirgantara } \\
\text { Indonesia }\end{array}$ & TAI & $\begin{array}{l}\text { Peningkatan avionik dan sayap untuk } \\
\text { pesawat-pesawat CN235. } \\
\text { Pengembangan, sertifikasi dan produksi } \\
\text { bersama pesawat N245. } \\
\text { Global supply chain untuk komponen } \\
\text { CN235. } \\
\text { Pengembangan bersama untuk pesawat } \\
\text { tanpa awak kelas Medium Altitude Long } \\
\text { Endurance (MALE). }\end{array}$ \\
\hline \multirow[t]{2}{*}{ PT. Pindad } & MKEK & Produksi amunisi dan laras senjata. \\
\hline & $\begin{array}{l}\text { STM, } \\
\text { bekerjasama } \\
\text { dengan } \\
\text { TKMS }\end{array}$ & Pembuatan kapal selam kelas 214. \\
\hline
\end{tabular}

\section{Kerjasama Pembuatan Medium Tank}

Kerjasama pembuatan Modern Medium-Weight Tank (MMWT) atau sering disebut Kaplan MT disepakati pada tahun 2014 oleh PT. Pindad dan Savunma Sistemleri A.Ş (FNSS). Kerjasama tersebut meliputi transfer teknologi, produksi lokal dan produksi bersama (Sunnetci, 2018). FNSS merupakan perusahaan patungan antara Nurol Holding Turki dengan BAE Systems Inggris dan memiliki pengalaman memproduksi kendaraan tempur sesuai dengan standar NATO. Kerjasama tersebut dimulai dengan pembuatan dua purwarupa Kaplan MT yang masing-masing diproduksi di Turki dan Indonesia sesuai dengan spesifikasi kebutuhan dan medan yang berbeda.

Kedua purwarupa tersebut telah selesai diproduksi dan telah memenuhi standar kelayakan dan kelulusan uji coba. Bagi Indonesia, Kaplan MT merupakan produksi domestik kendaraan tempur baja berantai untuk pertama kalinya. Indonesia dan Turki saat ini dalam tahap negosiasi untuk produksi masal Kaplan MT yang direncanakan rampung pada 2019 (Hurriyet Daily 2018). Produksi masal Kapalan MT akan diprioritaskan untuk kebutuhan domestik kedua negara dan kemudian untuk tujuan ekspor.

\section{Kerjasama Pembuatan Peralatan Komunikasi Militer}

Kerjasama dalam peralatan komunikasi militer disepakati pada 2017 oleh PT. Len dan Aselsan yang meliputi produksi bersama peralatan komunikasi militer untuk HF dan V/UHF teknologi software defined radio (PT. Len 2017). Aselsan merupakan perusahan elektronik pertahanan terbesar di Turki yang dimiliki oleh yayasan angkatan bersenjata Turki. Aselsan telah mampu memproduksi kebutuhan domestik peralatan 
elektronik yang digunakan oleh militer Turki sesuai dengan standar NATO sehingga memiliki reputasi ekspor yang baik (Aselsan 2018).

Kerjasama tersebut bertujuan meningkatkan kapasitas peralatan komunikasi militer di wilayah perbatasan dalam rangka menjaga keamanan wilayah kedaulatan. Indonesia melalui PT. Len sebelumnya telah memulai kerjasama di bidang teknologi pertahanan dengan Turki pada 2013 dalam memproduksi peralatan komunikasi pertahanan yang telah dipasang di perbatasan RI-Malaysia di Kalimantan Timur (PT. Len 2014, 72-73). Dengan kata lain, kerjasama tersebut merupakan kelanjutan dan perluasan kerjasama Indonesia dengan Turki yang pernah dilakukan sebelumnya.

\section{Kerjasama Pengembangan Aviasi Pertahanan}

PT. Dirgantara Indonesia dan Turkish Aerospace Industries (TAI) menyepakati kerjasama aviasi militer pada 2017. Kerjasama tersebut mencakup beberapa bidang seperti peningkatan avionik dan sayap untuk pesawat-pesawat CN235; pengembangan, sertifikasi dan produksi bersama pesawat N245; Global supply chain untuk komponen CN235; dan pengembangan bersama untuk pesawat tanpa awak kelas Medium Altitude Long Endurance (PTDI 2017). TAI termasuk perusahaan seratus besar pemain global dalam industri aviasi dan pertahanan yang telah berkontribusi dalam pemenuhan kebutuhan keamanan nasional (TAI 2017). Dalam kerjasama tersebut, Turki melalui TAI bertanggungjawab dalam peningkatan kualitas pesawat produksi Indonesia CN235 dan N245 serta membantu pemasaran karena negara tersebut memiliki reputasi sebagai salah satu eksporter alpalhankam signifikan di dunia. Indonesia juga diuntungkan dengan adanya kerjasama pengembangan pesawat tanpa awak (PTTA) atau unmanned aerial vehicle (UAV) tipe Medium Altitude Long Endurance (MALE). Keberadaan PTTA/UAV tersebut dibutuhkan oleh Indonesia untuk memantau dan menjaga keamanan wilayah territorialnya.

\section{Kerjasama Pembuatan Amunisi dan Laras Senjata}

Pemerintah Indonesia juga bekerjasama dalam hal produksi amunisi dan laras senjata dengan pemerintah Turki. Kerjasama tersebut dilaksanakan oleh PT. Pindad dan Mechanical and Chemical Industry Company (MKEK) yang disepakati pada 2017 (Kementerian Pertahanan, 2017). MKEK merupakan perusahaan penghasil amunisi dan laras senjata yang memehuhi standar NATO dan memiliki mitra ekspor di banyak negara. Kerjasama tersebut bertujuan memenuhi variasi amunisi dan laras senjata angkatan bersenjata Indonesia.

\section{Kerjasama Pembuatan Kapal Selam}

Kerjasama yang terbesar selain medium tank yang dilakukan oleh Indonesia dan Turki adalah pembuatan kapal selam tipe 214 untuk angkatan laut Indonesia (STM 2017). Dalam kerjasama tersebut, Turki menunjuk Savunma Teknolojileri Mühendislik ve Ticaret A.SS (STM) sebagai penanggungjawab proyek dengan menggandeng perusahaan Jerman ThyssenKrupp Marines Systems (TKMS). Produksi pertama kapal selam tersebut akan dilakukan di Turki dan akan dikirim ke Indonesia pada 2021. Sedangkan produksi dua kapal selam lainnya akan dilakukan di Indonesia. Dalam pembuatan kapal selam tersebut, Indonesia tidak sekedar menjadi pembeli, namun juga terlibat dalam proses produksinya sehingga ada jaminan alih teknologi.

Indonesia telah begitu lama mengabaikan keamanan maritim di tengah-tengah 
ketatnya anggaran dan struktur komando yang lebih berorientasi kontinental (Agastia 2017,164 ). Indonesia dengan wilayah lautannya yang luas membutuhkan kapal selam yang lebih modern dalam menjaga keamanan dan kedaulatan karena jumlah kapal selam yang dimiliki oleh Indonesia saat ini belum cukup untuk melakukan fungsi tersebut. Keberadaan kapal selam kerjasama Indonesia dengan Turki tersebut akan membantu memenuhi kemampuan minimum pertahanan khususnya di wilayah perairan Indonesia.

\section{Simpulan}

Adanya keterlibatan sipil dalam inovasi militer menghasilkan cara pandang baru bagaimana seharusnya politik luar negeri negara diarahkan untuk memberdayakan industri pertahanan domestik. Diplomasi pertahanan merupakan media untuk mengkomunikasikan kepentingan nasional tersebut. Bagi Indonesia, kerjasama industri pertahanan dengan Turki akan mampu meningkatkan kapasitas industri pertahanan domestik karena adanya transfer teknologi. Perkembangan teknologi pertahanan domestik akan mendorong peningkatan kemampuan deterrence Indonesia dalam menjaga integritas kedaulatannya, menjaga politik luar negeri yang independen dalam mewujudkankan stabilitas kawasan serta menjadi aktor penting dalam pasar persenjataan di masa yang akan datang.

Turki hanyalah salah satu negara yang menjadi mitra Indonesia dalam mewujudkan agenda inovasi tersebut. Sampai saat ini kerjasama industri pertahanan Indonesia dengan Turki masih terbatas pada medium tank, alat komunikasi militer, teknologi aviasi pertahanan, amunisi dan kapal selam. Walau demikian, kebijakan kerjasama tersebut mengindikasikan bahwa Indonesia mulai melebarkan politik luar negeri teknologi pertahanannya, tidak lagi hanya bergantung pada mitra tradisional. Peningkatan hubungan kedua negara menuju strategic bilateral partnership masih terbuka di masa yang akan datang mengingat peningkatan peran global politik luar negeri Turki.

Keberhasilan untuk Indonesia mengurangi ketergantungan pasokan alpalhankam dengan cara mengandalkan produksi domestik melalui kerjasama tentu belum dapat dilihat dalam waktu dekat apalagi kebijakan tersebut baru diperhatikan dalam satu dekade terakhir. Selain itu, inovasi militer Indonesia juga menghadapi berbagai tantangan seperti dominasi dan kepentingan major pawers, beban investasi yang harus dialokasikan bagi industri pertahanan domestik, dan reformasi industri pertahanan yang berkelanjutan.

\section{Referensi}

\section{Buku dan Bab dalam Buku}

Bakry, Umar Suryady, 2017. Metode Penelitian Hubungan Internasional. Yogyakarta: Pustaka Pelajar.

Cottey, Andrew, dan Anthony Forster, 2004. Reshaping Defence Diplomacy: New Roles for Military Cooperation and Assistance. London: Routledge. [e-book]. 
https://www.tandfonline.com/doi/pdf/10.1080/714027950

Gindarsah, Iis, dan Adhi Priamarizki, 2015. "Politics, Security and Defense in Indonesia: the Pursuit of Strategic Autonomy" dalam Roberts, Christopher B., at al., (Ed.), 2015. Indonesia's Ascent: Power, Leadership and the Regional Order. [e-book]. The UK: Palgrave Macmillan. https://link.springer.com/ chapter/10.1057/9781137397416_7

Millett, Allan R., 1996. "Patterns Of Military Innovation" dalam Murray, Williamson and Allan R. Millet (Ed.), 1996. Military Innovation in the Interwar Period. [e-book]. Cambridge: Cambridge University Press. https://trove.nla.gov.au/ work/5750269?selectedversion=NBD11956951

Murray, Williamson, 1996. "Innovation: Past and Future" dalam Murray, Williamson and Allan R. Millet (Ed.), 1996. Military Innovation in the Interwar Period. [e-book]. Cambridge: Cambridge University Press. https://trove.nla.gov.au/ work/5750269? selectedversion=NBD11956951

Posen, Barry R., 1984. The Sources of Military Doctrine. Ithaca, NY: Cornell University Press.

Raska, Michael, 2016. Military Innovation in Small States: Creating a Reverse Asymmetry. London: Routledge.

Sukma, Rizal, 2012. "Indonesia's Security Outlook and Defence Policy" dalam National Institute for Defense Studies (Ed.), 2012. Security Outlook of the Asia Pacific Countries and Its Implications for the Defense Sector. [e-book]. Japan: NIDS. http://www.nids.mod.go.jp/english/publication/joint_research/series7/ series7.html

\section{Jurnal dan Jurnal Daring}

Agastia, IGB. Dharma, 2017. "Small Navy, Big Responsibilities: The Struggles of Building Indonesia's Naval Power.” AEGIS: Journal of International Relations, 1(2), 164-180. http://e-journal.president.ac.id/presunivojs/index.php/AEGIS/ article/view/238

Ambros, Christiano Cruz, 2017. "Defense and Industrial Industry: Theoretical Controversies and Implications in Industrial Policy." AUSTRAL: Brazilian Journal of Strategy \& International Relations, 6(11), 132-153. https://doi. org/10.22456/2238-6912.74955

Amrullah, Muhammad Rizky, 2016. "Diplomasi Pertahanan Indonesia terhadap Turki: Studi Kasus Kerjasama Industri Pertahanan.” Jurnal Pertahanan dan Bela Negara, 6(1), 151-167. http://jurnal.idu.ac.id/index.php/JPBH/article/view/299

Bağc1, Hüseyin, dan Çağlar Kurç, 2016. “Turkey’s Strategic Choice: Buy or Make Weapons?” Defence Studies, 17(1), 1-25. doi: 10.1080/14702436.2016.1262742 
Bilgen, Hakki, 2010. "Competitiveness of Defense Industry in Turkey." International Journal of Economics and Finance Studies, 2(1), 63-70. http://dergipark.gov. $\operatorname{tr} /$ ijefs/issue/26156/275500

Hartati, Sri, at al., 2014. "Indonesian Defense Industry Model Concept: A Study Framework for Defense Industry Building." Journal of Advanced Management Science, 2(4), 260-266. doi:10.12720/joams.2.4.260-266

Hills, Alice, 2000. "Defence Diplomacy and Security Sector Reform." Contemporary Security Policy, 21(1), 46-67. doi: 10.1080/13523260008404244

Kurc, Caglar, dan Richard A. Bitzinger, 2019. "Defense industries in the 21st century: A comparative analysis-The second e-workshop." Comparative Strategy, 37(4), 255-259. doi: 10.1080/01495933.2018.1497318

Laksmana, Evan A., 2012. "Regional Order by Other Means? Examining the Rise of Defense Diplomacy in Southeast Asia.” Asian Security Journal, 8(3), 251-270. doi: $10.1080 / 14799855.2012 .723920$

Sari, Marina Ika, at al., 2018. "Indonesia-India Defense Diplomacy in the Indian Ocean.” Jurnal Pertahanan, 4(2), 77-88. http://jurnal.idu.ac.id/index.php/ DefenseJournal/article/view/403/marinaika

Sebastian, Leonard C., dan Iis Gindarsah, 2013. "Assessing military reform in Indonesia." Defense and Security Analysis, 29(4), 293-3017. doi: 10.1080/14751798.2013.842709

Tippe, Syarifudin, 2013. "Defense Offset Policy in Indonesia." Bisnis dan Birokrasi: Jurnal Ilmu Administrasi dan Organisasi, 20(2), 85-89. http://journal.ui.ac. id/index.php/jbb/article/view/3069/2401

\section{Undang-Undang dan Dokumen Resmi}

Buku Putih Pertahanan Indonesia, 2015. Jakarta: Kementerian Pertahanan RI. https://www.Kementerian Pertahanan.go.id/wp-content/uploads/2016/o4/ BPPI-INDO-2015.pdf

Kunjungan Kerja Komisi I DPR RI ke Turki, 2011. Jakarta: Komisi I DPR RI. http://www.dpr.go.id/dokakd/dokumen/K1_kunjungan_Kunjungan_Kerja_ Komisi_I_DPR_RI_ke_Turki.pdf

PT. Len, 2014. Laporan Tahunan: Membangun Keunggulan melalui Inovasi Teknologi untuk Pembangunan Berkelanjutan. bce.unpad.ac.id/wp-content/ uploads/2016/05/AR-Len-2014.pdf

Undang-Undang Republik Indonesia No. 19 Tahun 2014 tentang Pengesahan Persetujuan Kerjasama Industri Pertahanan antara Pemerintah Republik Indonesia dan Pemerintah Republik Turki, 2014. Jakarta: DPR RI 


\section{Artikel Daring}

Aselsan, 2018. "Quality Assurance Standard” [daring]. https://www.aselsan.com.tr/ en-us/about-us/Pages/Quality.aspx

Cooper, Jeffrey R., 1994. "Another View of the Revolution in Military Affairs." Strategic Studies Institute's Research Report, July 15. https://ssi.armywarcollege. edu/pdffiles/oo232.pdf

Gindarsah, Iis, 2015. "Indonesia's Defense Diplomacy: Harnessing the Hedging Strategy against Regional Uncertainties.” RSIS Working Papers, No. 293, June 9. https://www.rsis.edu.sg/rsis-publication/rsis/wp293/\#.XLl-4TAzbIV

Gleeson, Dennis J., 1998. "Contemplating Military Innovation.” Institute for Defense Analysies’ Research Report, August. https://apps.dtic.mil/dtic/tr/fulltext/u2/ a360738.pdf

Hurriyet Daily, 2018. "Turkish, Indonesian tank ready for mass production” [daring]. http://www.hurriyetdailynews.com/turkish-indonesian-tank-ready-for-mass-production-136535

Kementerian Pertahanan, 2017. "Industri Pertahanan Indonesia dan Uni Emirat Arab Kerjasama Produksi Senjata dan Tankboat" [daring]. https://www.Kementerian Pertahanan.go.id/2017/02/20/industri-pertahanan-indonesia-dan-uni-emirat-arab-kerjasama-produksi-senjata-dan-tankboat.html

KKIP, 2018. "Peran Komite Kebijakan Industri Pertahanan” [daring]. https://www. kkip.go.id/

Kuah, Adrian, dan Bernard Loo, 2014. "Examining the Defense Industrialization-Economic Growt Relationship: The Case of Singapore." RSIS Working Papers, No. 70, July. www.files.ethz.ch/isn/27158/WP70.pdf

MacGillivray, Iain, 2016. "Turkey's Defense Industry: A Burgeoning Powerhouse." Global Business Reports:Turkey Aerospace and Defense, March 21. Turkey: GBR Publication. https://www.gbreports.com/publication/turkey-aerospace-2016

Panjaitan, Luhut, 2016. "Menciptakan Stabilitas Melalui Peningkatan Pertahanan dan Pemerataan Ekonomi” disampaikan pada Kuliah Umum, 20 April. Jakarta: Universitas Indonesia. http://uiupdate.ui.ac.id/sites/default/files/Strategy\%20 Teknologi\%20UI-final\%20\%28V2\%29.pdf

PT. Len, 2017. "Len-Aselsan Teken Joint Production Radio Militer HF dan V/UHF SDR" [daring]. https://www.len.co.id/len-aselsan-teken-joint-productionradio-militer-dan-vuhf-sdr/ 
PTDI, 2017. "PTDI dan Turkish Aerospace Industries Kerjasama Pengembangan Pesawat" [daring]. http://www.bumn.go.id/ptdi/berita/1-PTDI-dan-Turkish-Aerospace-Industries-Kerjasama-Pengembangan-Pesawat-

Sanyal, Joyo, 2018. "Building Strategic Security: Defence Diplomacy and the Role of Army" [daring]. https://www.aspistrategist.org.au/building-strategic-securitydefence-diplomacy-and-the-role-of-army/

SIPRI, 2018. "Trends in International Arms Transfers." SIPRI Fact Sheet, March. https://www.sipri.org/sites/default/files/2018-03/fssipri_at2017_o.pdf

STM, 2017. "STM leaves its mark on IDEF 2017" [daring]. https://www.stm.com.tr/ en/news/announcement/stm-leaves-its-mark-on-idef-2017?fbclid=IwAR257r5 LwgFffE7t8n19L2sEG67rpVOdAYWRoVAfic1d6Vv_uN2xJHDoBao

Sunnetci, Ibrahim, 2018. "A Look at the Turkish Defense Industry Land Platforms/ Systems Sector" [daring]. http://www.defenceturkey.com/en/content/alook-at-the-turkish-defense-industry-land-platforms-systems-sector-3027\#. XCnk2FUzbIV

TAI, 2017. "Corporate Profile" [daring]. https://www.tai.com.tr/en/corporate/aboutus

Winger, Gregory, 2014. “The Velvet Gauntlet: A Theory of Defense Diplomacy.” IWM Junior Visiting Fellows' Conferences, Vol. XXXIII, May 15. https://www.iwm. at/publications/5-junior-visiting-fellows-conferences/vol-xxxiii/the-velvetgauntlet/ 
Civil Participation in Military Innovation:

Cooperation between the Defense Industry of Indonesia and Turkey 2010-2018 